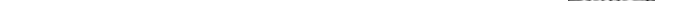





\title{
La narración de la memoria Aymenu (Uitoto) en la pintura de Rember Yahuarcani
}

\author{
Luisa Elvira Belaunde
}

"La identidad está en el sentimiento y el pensamiento" Con estas palabras Rember Yahuarcani, pintor de 22 años, nacido a orillas del río Amazonas en el Perú, explica la fuerza de convicción que lo lleva a narrar por medio de la pintura las historias antiguas que escuchó de su abuela paterna. Proveniente de Pebas, cerca de la frontera con Colombia y Brasil, Rember es el producto del mestizaje entre los grupos étnicos y las nacionalidades del lugar. Uitotos, Cocamas, Tikunas, colombianos, brasileños y peruanos, todos estos ancestros convergen en él. Su pintura también materializa esta confluencia de vidas y culturas arrojadas por la historia a lo largo del gran río que hoy las une. De su abuela materna, concibió el deseo de contar la memoria de los Aymenu, un clan uitoto ${ }^{2}$ originario de la Chorrera en el Caquetá Colombiano, que fue desplazado hacia el Perú en los tiempos del caucho, bajo el mando de la Casa Arana ${ }^{3}$. De su abuelo paterno, heredó el apellido Cocama Yahuarcani, que lo identifica al "clan del jaguar". De su padre aprendió a tallar madera y pintar sobre cortezas de árbol con tintes naturales para ganarse la vida. De su madre, recibió el legado tikuna y las costumbres del vecino país, Brasil, del que proviene. Así se fueron mezclando los conocimientos de sus antepasados con los que fue criado. Pero, es al lado de los Aymenu que se alimenta su imaginación para expresar a colores la historia de la gente, las plantas, los animales y los dioses de su abuela.

\section{De la artesanía al arte}

Este es el caso de un artista forjado por la práctica de la artesanía familiar. En casa de Rember todo el mundo está

La autora es profesora en la Maestría en Estudios Amazónicos de la Universidad Nacional Mayor de San Marcos e investigadora asociada al Centro de Antropología Amazónica de Aplicación Práctica (CAAAP), Perú. luisaelvira@yahoo.com 
siempre con las manos a la obra. Su padre talla una máscara de rana en un tronco madera de topa, su madre enfila escamas de pescado, semillas y plumas para hacer collares, su hermana arma muñecas de hierba, y su hermano dibuja sobre calabazas el rostro de un espíritu protector del tabaco. Al final de cada día, en el cuarto central de esta casa-taller se empilan artefactos coloridos para surtir los estantes de las tiendas en el puerto, a donde paran los botes llevando a los turistas. Pero según Rember, no se trata solamente de hacer un producto en serie que se pierda en el anonimato y la exotización alienante del consumo turístico ${ }^{4}$. Durante toda su niñez y adolescencia, el también produjo artesanías para contribuir a la economía familiar. Hoy en día, prefiere dedicarse a realizar obras únicas que intenten disolver el halo de incomprensión entre "nosotros" y "ellos", y hagan escuchar por medio de imágenes las voces por tanto tiempo aplacadas de los Aymenu.

Para Rember, afirmarse como un artista amazónico en la Amazonía y en la capital del país, Lima, en donde se concentra el mercado del arte nacional, es una vocación nacida en respuesta a la formación que recibió de su abuela y la creatividad artesana de toda su familia. "Los indígenas somos afortunados porque sabemos de dónde venimos. Mucha gente en Lima no sabe de dónde viene", nos dice. Sin embargo, en Pebas tampoco es fácil reconocerse como nativo porque la gran mayoría de los jóvenes de su generación prefieren aunarse a las hondas de un mestizaje Amazónico pujante que acalla los recuerdos de los antiguos con la letra de su música electrónica y el consumismo de mercancías baratas. "Si miras en el diccionario, ves que todo el mundo es nativo, de algún lugar", explica nuestro artista, a sabiendas que lo que lo motiva es, probablemente, un sentimiento universal. "Pero, si dices que eres nativo, te dan duro. Por eso muchos jóvenes no se reconocen de ninguna etnia". Así es como, nadando a contra corriente del anti-indigenismo de moda, Rember crea obras figurativas en las que mezcla de manera innovadora técnicas y cánones estéticos occidentales e indígenas.

La pintura figurativa sobre lienzo es de reciente popularidad entre los pueblos nativos del río Amazonas. En parte, el surgimiento de artistas como Rember se hizo posible gracias a la apropiación por parte de la población local del arte figurativo que ilustra los libros escolares y religiosos, y a la demanda del turismo por lienzos pintados con motivos amazónicos. En el pasado, entre los Aymenu, así como los otros grupos étnicos del lugar, antes que la influencia de la escuela obligatoria se expandiera, la pintura era principalmente un arte corporal de diseños no-figurativos ${ }^{5}$. Los lienzos utilizados, por así decir, eran los cuerpos

248 Luisa Elvira BELAUNDE. La Narración de la memoria Aymenu (Uitoto) en... 
tridimensionales de la gente, y los artistas eran eminentemente mujeres. Para las grandes festividades, las mujeres solían cubrir la piel de los participantes con líneas y curvas, formando diseños abstractos pintados con tintes naturales a base de plantas y diversos tipos de arcillas y lodos. Hoy en día, esta pintura corporal solo es revivida ocasionalmente para los bailes folklóricos de las celebraciones escolares, y el arte de la pintura se ha desplazado de la piel de la gente a la piel de los árboles. En efecto, en la actualidad, el lienzo favorito de los pintores indígenas ${ }^{6}$ es una corteza procesada artesanalmente llamada llanchama. Esta corteza es extraída manualmente del tronco de los árboles de ojé (Ficus insipida), extendida, secada al sol y utilizada como una superficie plana para pintar ${ }^{7}$.

\section{Darle imagen visible a lo invisible}

La mayor parte de la pintura sobre llanchama producida en Pebas y otros lugares vecinos, está dirigida al mercado turístico y se basa sobre reproducciones de escenas típicas, paisajes y detalles de la flora y la fauna de la localidad. Pero para pintores como Rember y los miembros de su familia, detrás de cada nueva pintura, hay todo un proceso de transformación de lo invisible en lo visible. No se trata simplemente de reproducir imágenes del entorno, sino más bien, de encontrar una imagen figurativa con la cual hacer visibles a los espíritus y los dioses, que son, por lo general, invisibles y solo se manifiestan en imágenes en visiones durante sueños y experiencias visionarias inducidas por la ingestión de sustancias psicoactivas ${ }^{8}$. Otra manera de conocerlos, e imaginarlos, es a través de las narraciones de las experiencias de los antiguos y la mitología.

Las pinturas de Rember muestran el universo aymenu colocando en imágenes aquello sobre lo que escuchó hablar: la explotación durante el boom del caucho, los grandes rituales y festividades, las hazañas de curanderos y hechiceros, los espíritus que gobiernan el entorno, y el ser creador superior que se da a conocer por su nombre: Buinaima, "Soy Quien Yo Soy". Pinta sobre la llanchama con un palito fino, utilizando una mezcla de pinturas acrilicas y de resinas y tintes naturales extraídos de los alrededores: pepas de achiote (Bixa orellana) para el rojo tinto, tinta de huito (Genipa americana) para el negro, fruto de huitillo (Dialium guianense) para el morado, hoja de pifuayo (Bactris gasipaes) para el verde, fruto de guisador (Curcuma longa) para el anaranjado, y varios barros de colores para el blanco, el gris, el crema y el amarillo. De esta manera, así como los temas que pinta, la mayoría de los materiales que usa para hacer sus obras son parte viviente de la Amazonía. 
Junto a su padre, Rember aprendió a darle imagen a los espíritus y personajes míticos, retándose el uno al otro en un ejercicio de creatividad conceptual y plástica. "En las historias antiguas este espíritu es así, así, así. Yo lo podría hacer así. ¿Tu cómo lo harías?", le decía su padre. Entre juegos, los espíritus fueron cobraron cuerpos pintados para que nosotros, citadinos, podamos contemplar estos seres venidos de una dimensión desconocida. Según nuestro artista, sin embargo, sus obras de arte no tienen por objetivo deslumbrar al que las ve, sino llegar al centro de su ser, el cual en la concepción del ser humano aymenu se encuentra en el corazón. "Si la gente me va a ver como algo raro, exótico, mejor no hago nada", nos dice. Yo quisiera hacer nacer en un pedacito de su corazón un sentimiento hacia nosotros, y quizás más adelante, que nos respeten."

\section{Palabra e imagen}

La conjunción de la palabra y la imagen habita todas sus obras, y esta narratividad se vuelve aún más evidente cuando la historia contenida en la imagen es explicitada en nuevas narraciones. A continuación mostramos tres obras acompañadas de cortos narrados por Rember, en los que el autor traduce de vuelta la imagen a la palabra, para que al ver las pinturas, el observador también pueda escuchar las historias que él escuchó de su abuela.

Yo hoy veo a los mitos como caminos. Uno da origen a otro, pero es un solo gran camino que nos lleva a entender como son las cosas. Los mitos van apareciendo en mis cuadros, cuando los voy entendiendo. Los pinto para no olvidarlos. (Rember Yahuarcani)

Comenzamos por una representación de la historia de Luna y su hermana, la pareja incestuosa primordial de la mitología aymenu, que fue rechazada por los suyos y condenada a errar por los bosques. Rember artista pinta y cuenta algunos pasajes de este mito: 


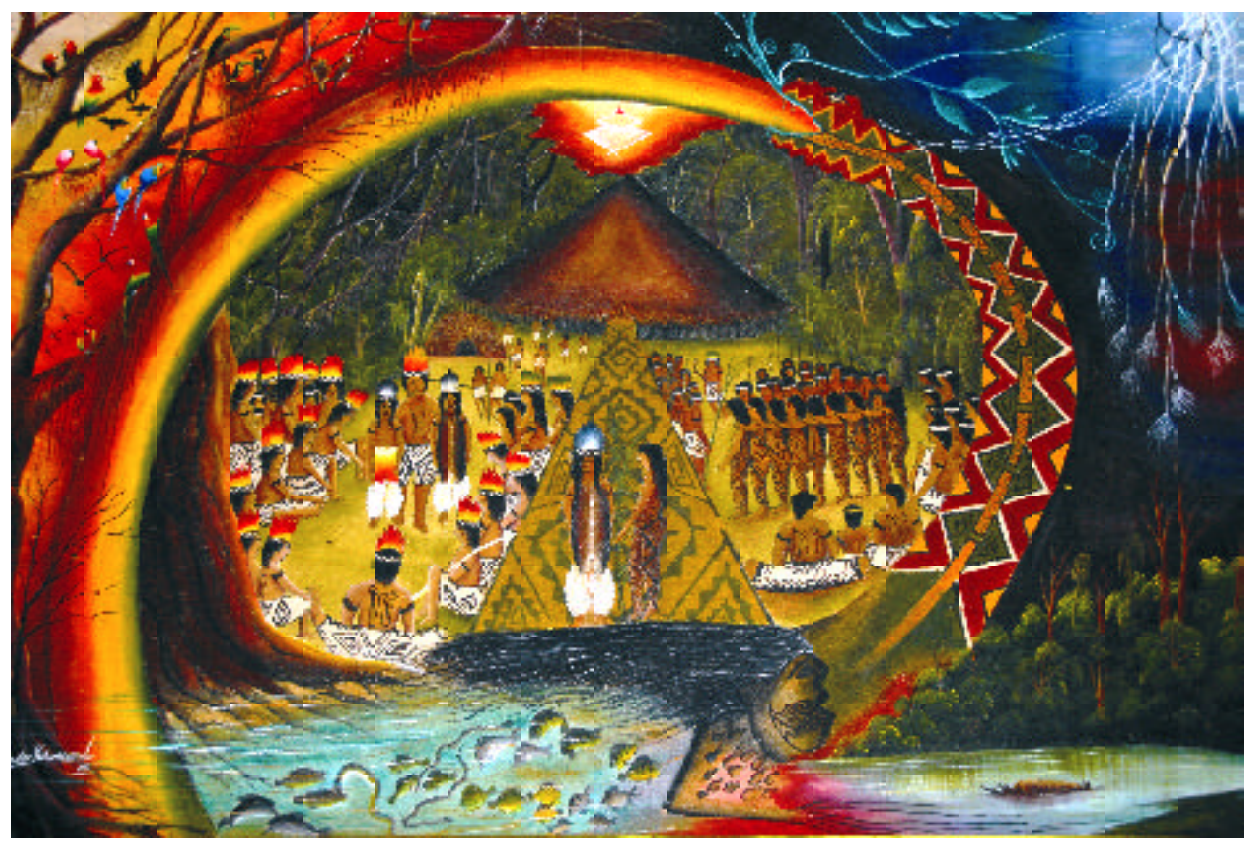

"Cosmovisao femenina", $90 \mathrm{~cm}$ X $100 \mathrm{~cm}$, acervo Luisa Elvira Belaunde (tintes naturales y acrílicos sobre llanchama - 2006)

La hermana de Luna tiene un bosque dentro de su cabello, que es donde ocurre toda la historia: todos los bosques que tuvo que recorrer mientras buscaba a su familia. Y mientras lo hacía, mientras recorría el mundo, su pelo lloraba por las noches, y rociaba agua sobre la tierra. Por eso cuando nos levantamos de madrugada todo le suelo está cubierto de rocío. En su cuerpo están impresas de las marcas de los jaguares que se la comieron. (Rember Yahuarcani)

La segunda pintura muestra un aspecto de la cosmovisión aymenu sobre la flora, en particular sobre el veneno utilizado en la tecnología de la pesca colectiva. El barbasco (Phaseolus singapou) es un arbusto de cuyas raíces se extrae la sabia para envenenar a los peces en los ríos pequeños. Aquí vemos al "dueño del barbasco", su espíritu guardián, bajo forma humana. 


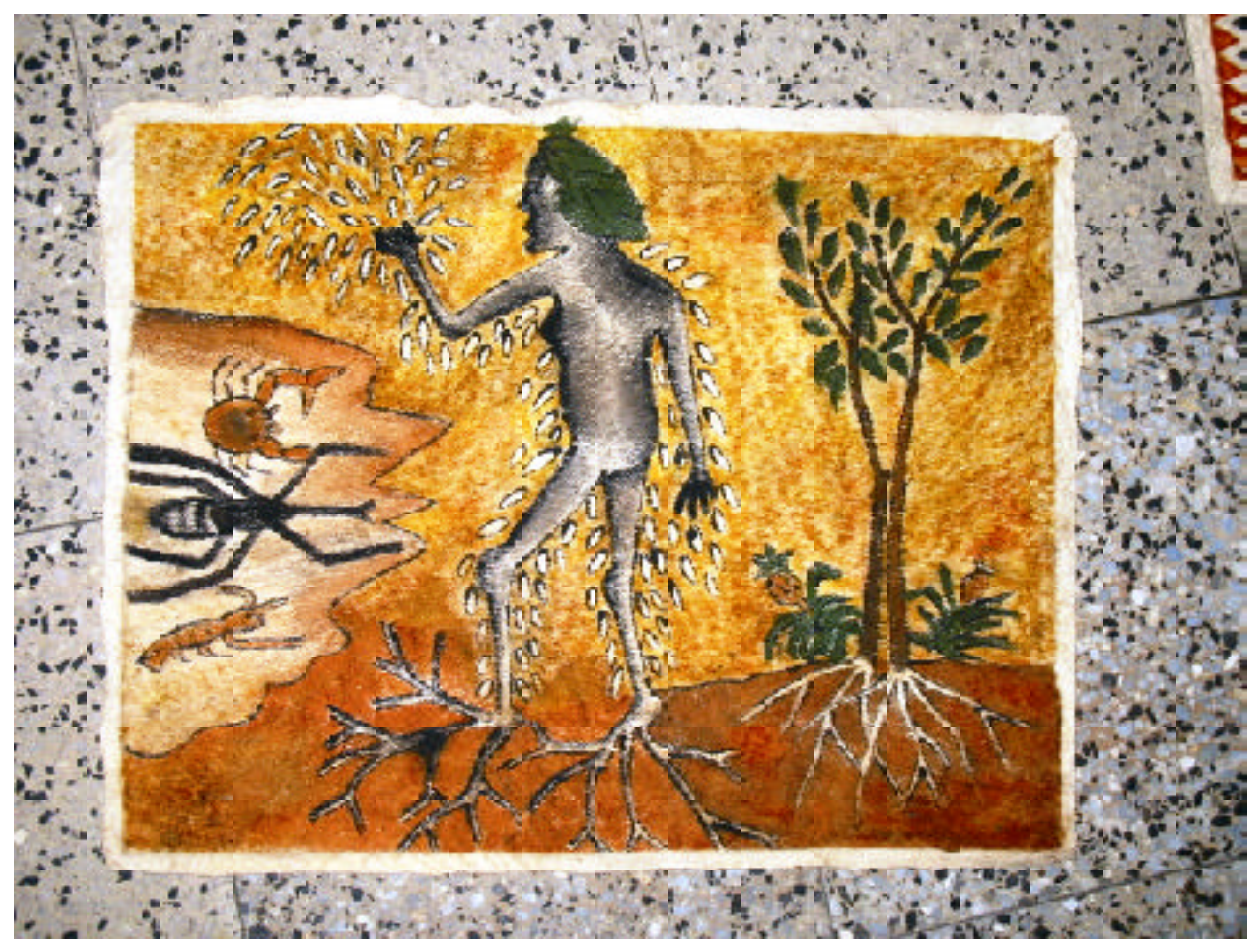

"El Dono del Barbasco", 40cm X 50cm, acervo Lucha del Aguila (tintes naturales sobre llanchama - 2006)

El barbasco es un hombre delgado que tiene pies que se convierten en raíces y cabello en forma de hoja. Cuando suda, gotea veneno, y envenena a todos, incluso a los humanos. Tiene tres enemigos inmunes a su veneno, las arañas de río, los camarones y los cangrejos. Nadie sabe por qué. (Rember Yahuarcani)

Para terminar, tenemos un retrato de las costumbres festivas aymenu. En el pasado, las mujeres eran el centro de dos grandes festividades: la celebración de la menarquia, a la izquierda, y la fiesta de los muertos, a la derecha. En ambas fiestas, sus cuerpos, especialmente sus nalgas y muslos, eran cubiertos con diseños geométricos en zigzag asociados al maní. Como esta semilla, que rebrota cuando se le coloca en el agua, según el pensamiento aymenu, la mujer es un ser surgido del agua para permitir que rebroten las generaciones, uniendo de esta manera la vida a la muerte, y el agua, a la tierra y al cielo ${ }^{9}$. Por esto, el mundo femenino está bajo la protección de la boa arco-iris cósmica.

252 Luisa Elvira BELAUNDE. La Narración de la memoria Aymenu (Uitoto) en... 


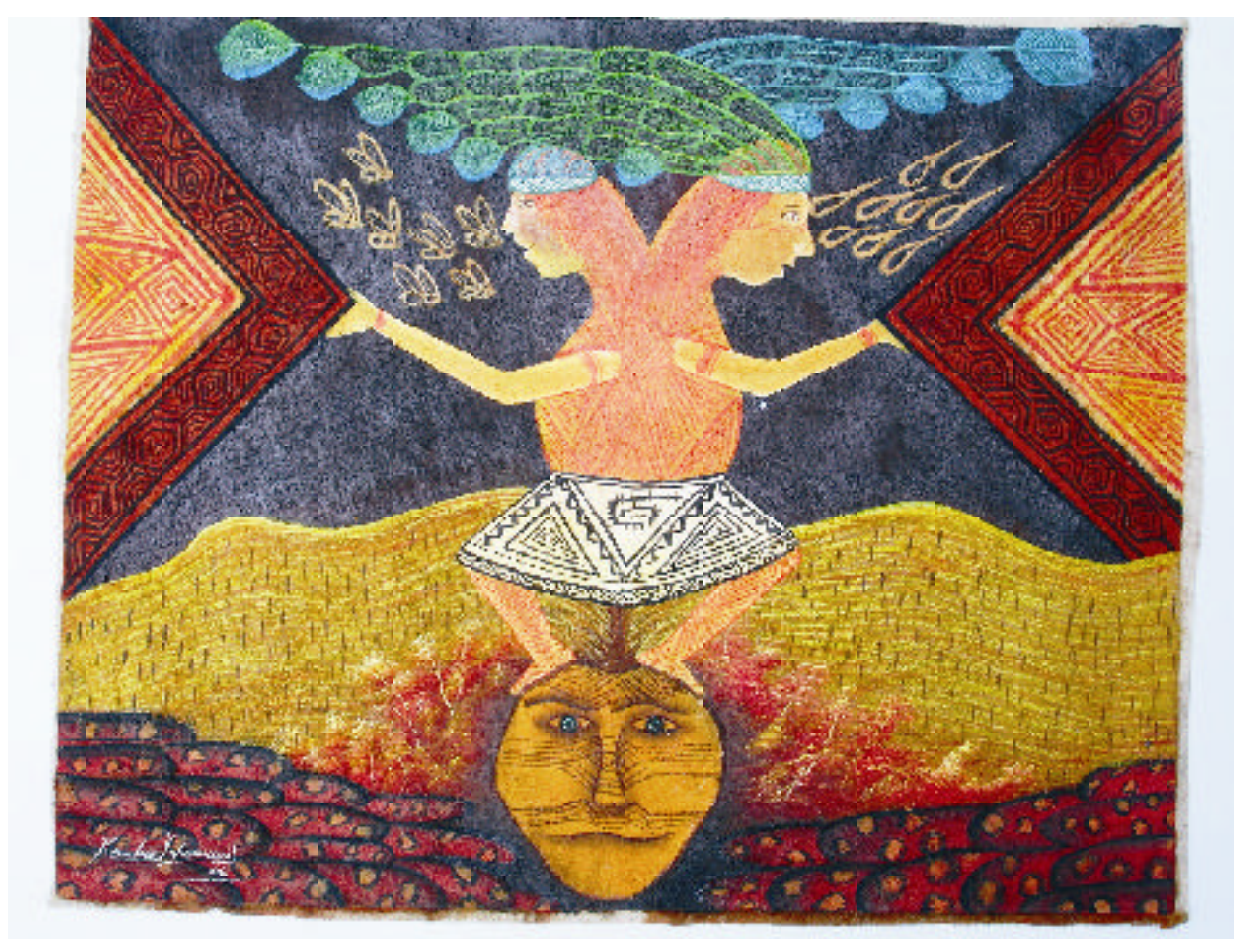

"Luna y su hermana", 40cm X 50cm, acervo Rember Yahuarcani (tintes naturales y acrílico sobre llanchama - 2004)

La mujer también es identificada con la boa amarilla, que vive en el agua y sale de vez en cuando a deslizarse por el mundo. Es un símbolo de belleza, y la mujer que se identifica con la boa es bella y esbelta. De la boca de la boa sale el arco-iris, que se eleva desde el agua para sostener al cielo, para que no se caiga sobre la tierra. (Rember Yahuarcani)

Pintor y cuenta cuentos, sus palabras abren ventanas en las imágenes, y remiten al observador a la poética entretejida en la cosmovisión y la memoria histórica.

Para Rember, este narrar con imágenes y palabras es una búsqueda de respeto al darse a escuchar en el medio socio-político regional que los mantuvo silenciados después del traumático traslado del clan aymenu a las orillas del Amazonas. No se trata solamente de respeto por el artista individual, sino de respeto por la transmisión de la memoria de los pueblos indígenas.

Cuando yo hablo de las historias, yo también les tengo un respeto. Porque las historias que yo sé, no son mías, sino que pertenecen a la comunidad, a toda la gente, $y$ han tomado mucho tiempo para juntarse. No son mías, son de todos. Quizás yo sea solamente un nexo entre la 
comunidad y la gente de Lima, para exigir un poco de respeto. (Rember Yahuarcani)

\section{Notas}

${ }^{1}$ Este articulo es el resultado de varias entrevistas con Rember Yahuarcani y del trabajo de recopilación de pinturas y textos llevados a cabo por el artista en asociación con el Colectivo Aents, al cual también pertenezco (Colectivoaents.blogspot.com). Agradezco a los otros miembros del Colectivo Aents, en particular a Fiorela Pucliefi y Kike Basurto Carvo por el trabajo efectuado.

${ }^{2}$ Los Uitoto o Huitoto (también llamados Iitoto en el Brasil), tienen una población total aproximada de 8500 y habitan en el área fronteriza entre Perú, Colombia y Brasil, entre los ríos Napo, Caquetá (Iça en el Brasil) y Amazonas (Solimões en el Brasil). En la Chorrera, Colombia, la mayoría de población uitoto pertenece al clan Aymenu, pero en Pebas, Perú, es probable que la abuela materna de Rember sea la única representante. Rember traduce el nombre del clan Aymenu como "Gente del Cielo". En Colombia, también se traduce como "Gente Garza" (Echeverri, comunicación personal).

${ }^{3}$ Ver Pineda (1985) para un recuento de la historia esclavista entre los Uitoto del Caquetá desde la perspectiva indígena.

${ }^{4}$ Ver Gallego (2003) para un estudio del turismo entre las familias Yagua cercanos a Pebas. Todavía no existe un estudio de la producción artesanal en Pebas.

${ }^{5}$ Ver Karadimas (2005, p. 195) para una interpretación de la pintura femenina entre los Miraña, vecinos cercanos de los Uitoto, y también Lagrou (2007) para un estudio teórico sobre diseño e imagen entre los Cashinahua.

${ }^{6}$ Otro importante pintor sobre llanchama es el finado Victor Churray, perteneciente al grupo étnico Bora y también nacido cerca de Pebas. Ver Belaunde (2007), Landolt (2005), Yllia (2005), y Cornejo Chaparro (2005) para estudios sobre la pintura indígena Amazónica contemporánea en el Perú.

${ }^{7}$ Entre algunos grupos étnicos del lugar, la llanchama servía de soporte para hacer ropas y máscaras pintadas que cubrían el cuerpo de los danzantes. Por ejemplo, hasta el día de hoy, los Tikuna hacen máscaras de llanchama pintadas con el rostro de diversos espíritus para la celebración de la menarquia de las muchachas y para la venta a los turistas (Goulard,1998). Pero la gran diferencia entre este uso ritual de la llanchama y el uso dado actualmente por artistas como Rember, es que estos últimos utilizan la llanchama como un soporte material bidimensional de dibujos figurativos.

${ }^{8}$ Entre los Aymenu, la principal sustancia psicoactiva es una pasta de tabaco con sal de monte llamado ampiri o ambil (en Colombia). Ver Echeverri (2000) para un estudio de la cosmovisión asociada a la fabricación y utilización del ampiri entre otros clanes Uitoto.

${ }^{9}$ Una idea semejante sobre el mani y la mujer se encuentra entre los Cashinahua. (McCallum 2001, p. 45)

254 Luisa Elvira BELAUNDE. La Narración de la memoria Aymenu (Uitoto) en... 


\section{Referencias}

BELAUNDE, Luisa Elvira. El brillo de los tintes de la selva: la pintura de Roldán Pinedo, maestro shipibo. Gaceta Cultural del Perú, Lima, n. 28, p. 24-5, 2007.

CORNEJO CHAPARRO, Manuel. El Mundo mítico amazónico. El Peruano, Lima, diario oficial, suplemento, v. 97, n. 4, p. 6-7, 2005.

ECHEVERRI, Juan Alvaro. The first love of a young man: salt and sexual education among the Uitoto indians of Lowland Colombia. In: OVERING, Joanna; PASSES, Alan (Eds.). The Anthropology of Love and Anger: The aesthetics of conviviality in native Amazonia. Londres: Routledge, 2000, p. 33-45.

GALLEGO, Lina María. El tejido de la vida: Acercamiento etnográfico al tejido de chambira de la comunidad yagua de la Libertad. Tesis (Grado en Antropologia) Universidad Nacional de Antioquia, Medellín, 2003.

GOULARD, Jean Pierre. Les genres du corps: conception de la personne chez les Ticuna de la haute Amazonie. Tesis (Doctorado en Antropología) - EHESS, Paris, 1998.

YLLIA, María Eugenia. Amazonía al descubierto: dueños, costumbres y visiones. En El Peruano, Lima, diario oficial, suplemento, v. 97, n. 4, p. 8-9, 2005.

KARADIMAS, Dimitri. La raison du corps: Idéologie du corps et représentations de l'environment chez les Miraña d'Amazonie colombienne. Paris-Leuve: Editions Peeters, 2005.

LAGROU, Elsje. A Fluidez da Forma: Arte, Alteridade e Agência em uma Sociedade Amazônica (Kaxinawa). Rio de Janeiro: Top Books, 2007.

LANDOLT, Gretna, El Ojo que cuenta: mitos y costumbres de la Amazonía indígena ilustrados por su gente. Lima: ICAM, 2005

LONDOÑO, Carlos. Muinane: un proyecto moral a perpetuidad. Medellín: Editorial de la Universidad de Antioquia, 2004.

MCCALLUM, Cecilia. Gender and sociality in Amazonia. How real people are made. Oxford: Berg, 2001.

PINEDA, Carlos. Historia oral y proceso esclavista en el Caquetá. Bogotá: Fundaciones de Investigaciones Arqueológicas Nacionales, Banco de la República, 1985.

TESSMANN, Gunter. Los indígenas del Perú nor-oriental: investigaciones fundamentales para un estudio sistemático de la cultura (1930). Quito: Abya-Yala, 1999.

Recebido em 29 de janeiro de 2008. Aprovado para publicação em 08 de fevereiro de 2008. 
